\title{
COUPLED THERMAL ANALYSIS OF CARBON LAYERS DEPOSITED ON ALUMINA NANOFIBRES
}

\author{
Vera S. Solodovnichenko ${ }^{\mathrm{a}}$, Mikhail M. Simunin ${ }^{\mathrm{b}}$, \\ Denis V. Lebedev ${ }^{c}$, Anton S. Voronin ${ }^{\mathrm{d}}$, Aleksei V. Emelianov ${ }^{\mathrm{e}}$, \\ Yuri L. Mikhlinf, Vladimir A. Parfenov ${ }^{\mathrm{f}}$, Ilya I. Ryzhkov ${ }^{\mathrm{a}, \mathrm{b}}$
}

\begin{abstract}
${ }^{a}$ Institute of Computational Modelling SB RAS, Federal Research Center KSC SB RAS, Akademgorodok 50-44, Krasnoyarsk, Russia

${ }^{b}$ Siberian Federal University, Svobodny 79, 660041 Krasnoyarsk, Russia

${ }^{c}$ Saint Petersburg State University, 7/9 Universitetskaya nab., St. Petersburg, 199034 Russia

${ }^{d}$ Federal Research Center KSC SB RAS, Akademgorodok 50, Krasnoyarsk, Russia

${ }^{e}$ National Research University of Electronic Technology - MIET, Shokin square 1, Zelenograd, Moscow, Russia

${ }^{f}$ Institute of Chemistry and Chemical Technology, Federal Research Center KSC SB RAS, Akademgorodok 50-24, Krasnoyarsk, Russia
\end{abstract}

\begin{abstract}
Catalyst-free chemical vapor deposition is used to form thin (1-2 nm) carbon layers on the surface of alumina nanofibers resulting in carbon-alumina nanocomposites. Thermal analysis, Xray fluorescent microanalysis, Raman spectroscopy, and electrical resistance measurements of these composites show that increasing of synthesis time not only increases the amount of carbon on alumina surface, but also the ordering and density of the carbon layers. Nitrogen adsorption data reveal the decrease of total pore volume with increasing the synthesis time. The obtained composite material could be employed for the preparation of ion-selective membranes with switchable ion transport, electroconductive ceramics, and electrochemical sensors.
\end{abstract}

Keywords: chemical vapor deposition, catalyst-free synthesis, alumina nanofibers, carbon layers.

\section{Introduction}

Chemical vapor deposition (CVD) is one of the most popular methods for synthesis of carbon structures. A wide range of carbon materials has been produced by this method [1]. The catalytic or template CVD are mainly used nowadays. However, these methods include removal of catalyst or template from the resultant products making the technique complicated and costly. 
Considering factors of operation and costs, non-catalytic or metal-free CVD appear to be the best choice. Various types of non-catalytic CVD have already been used to obtain carbon nanotubes $[2,3]$ or graphitic structures [4]. This method opens up new ways of producing novel types of nanocomposites, which combine the properties of substrate and carbon structure [5]. For example, a composite alumina - CNT material containing one nanotube for each channel was obtained by metal-free CVD on the anodic alumina [6]. This composite material showed controlled molecular transport characteristics and could be employed for the preparation of composite membranes with controlled physical and chemical properties [7].

Metal-free CVD also is widely used to form carbon layered structures including carbon nanosheets (nanowalls) [8-10] and graphene structures [11-13]. It provides the opportunity to produce carbon-coated materials suitable for various applications [14].

Diversity of resulting materials is achieved by changing the CVD conditions and using different types of substrates. The metal-free CVD synthesis of graphene has been tested on different kinds of substrates including quartz $[12,15,16]$, glass $[17,18], \mathrm{SiO}_{2}[12,16,19], \mathrm{MgO}$ and $\mathrm{ZrO}_{2}[20], \mathrm{Si}_{3} \mathrm{~N}_{4}[12,21]$ and $\mathrm{Ge} / \mathrm{Si}[22]$, which result in graphitic carbon or nanocrystalline graphene. A number of works reported the synthesis of carbon layered and graphene structures on $\mathrm{Al}_{2} \mathrm{O}_{3}[12,15,23,24]$. Mostly graphene-like structures were synthesized by plasma-enhanced CVD. The 3D graphene structures were produced on nanoporous anodic alumina by plasmaenhanced chemical vapor deposition [25]. Atomic layer deposited (ALD) $\mathrm{Al}_{2} \mathrm{O}_{3}$ was shown to be an effective substrate for nanocrystalline graphene direct synthesis. Nanocrystalline graphene with a size of about tens of nanometers has been grown on ALD alumina at a relatively low temperature of $550{ }^{\circ} \mathrm{C}$ by remote plasma enhanced CVD using pure methane as a precursor [26]. A large number of studies in this field performed CVD on sapphire [12, 15, 23]. Atmospheric-pressure CVD on sapphire between 1450 and $1650{ }^{\circ} \mathrm{C}$ with $\mathrm{CH}_{4}$ as precursor was used to form both monolayer and few-layer graphene $[27,28]$. Nanocrystalline graphene on sapphire was obtained by low pressure carbon dioxide-assisted CVD [29].

Uniform and continuous graphene films on different insulating substrates (including $\mathrm{Al}_{2} \mathrm{O}_{3}$ ) were produced by microwave plasma-enhanced CVD at a relatively low temperature of $700-750{ }^{\circ} \mathrm{C}$. The low activation energy barrier of $\mathrm{Al}_{2} \mathrm{O}_{3}$ proves it to be a more suitable substrate for the metal-catalyst-free growth of graphene at low temperature [30].

Recently, a novel type of alumina nanomaterial has been synthesized by ANF Technologies [31]. This material (Nafen ${ }^{\mathrm{TM}}$ ) is composed of $\gamma$-alumina nanofibers with the diameter of 10-20 $\mathrm{nm}$ and extremely high aspect ratios (up to $10^{6}$, the nanofiber length is in the cm range). Due to its unique aspect ratio and thermal stability up to $1250{ }^{\circ} \mathrm{C}$ [32], the Nafen material could be a promising support for few-layered graphene synthesis on its surface. This idea was realized 
previously in $[33,34]$. The resulting composite material showed excellent properties as an electrocatalyst support for Pt particles in fuel cells, and as a novel type of filler for electroconductive ceramics. The same approach was used later to form a network of graphenedecorated oxide ceramic nanofibers with tailored graphitic edges for ultrasensitive electrochemical sensors with high stability [35].

Recently, we have proposed a novel type of ion-selective membranes based on carboncoated Nafen nanofibers, which combine the advantages of ceramic nanofibrous media with good electrical conductivity $[36,37]$. These composite membranes demonstrate high ionic selectivity and appear to be very promising for nano- and ultrafiltration, separation of charged species, and switchable ion-transport selectivity [38-40]. To be able to control selective properties of membrane, a detailed study of carbon structure and its dependence on synthesis regimes is necessary. In contrast to spectroscopy, which provides generalized (or integral) structure information, the thermal study in air atmosphere can give information about the differences in structure along the thickness of a carbon layer. The comprehensive thermal analysis of Nafen ${ }^{\mathrm{TM}}$ alumina nanofibers was reported previously in [32]. It was also used for analyzing the procedure of nanofibers doping by zirconia and alpha-alumina by in situ chemical liquid deposition (CLD) technique [41]. The coupled thermal analysis (TG-DSC-FTIR) was shown to be an effective instrument for better understanding the synthesis procedure and optimizing the applied conditions.

In this work, we employ the coupled thermal analysis for studying the properties of carboncoated alumina nanocomposites and understanding the impact of CVD deposition time on the structure and properties of carbon layers on Nafen alumina nanofibers.

\section{Materials and methods}

\subsection{Materials synthesis}

To provide a nanoscale framework for CVD synthesis, Nafen nanofibers were dispersed in deionized water (the weight ratio Nafen:water was 1:200), and agitated with a magnetic stirrer for 30 minutes followed by 15 minutes of ultrasonic treatment (Sonics \& Materials VC-505, USA). The suspensions were filtered through the rough Teflon filters (average pore size about $0.6 \mu \mathrm{m}$ ) and dried in air. The resulting samples were obtained in the form of circular discs with the diameter of $40 \mathrm{~mm}$. For further removal of water by evaporation, the samples were sintered at $800{ }^{\circ} \mathrm{C}$ during 4 hours.

Synthesis of carbon layers was conducted in the CVD reactor (OTF-1500X-UL-3, MTI Corp., USA) at $900{ }^{\circ} \mathrm{C}$ (heating rate of $20-30^{\circ} \mathrm{C} / \mathrm{min}$ ) in propane/nitrogen mixture $(1 / 15)$ with the total flow rate of $4000 \mathrm{~cm}^{3} /$ min during the specified time (to be described below). Then the samples 

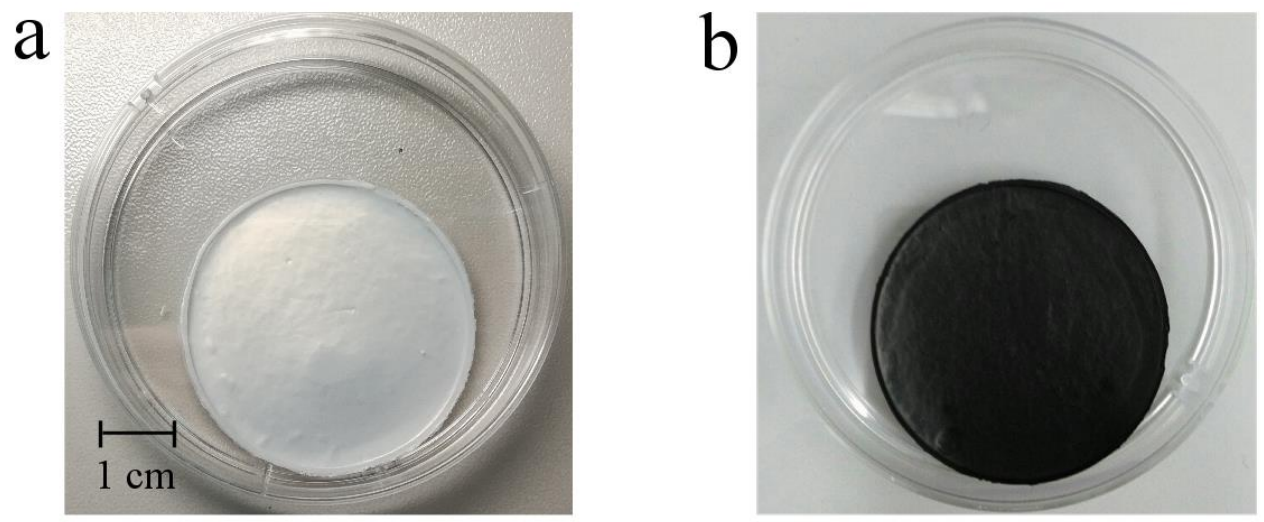

Fig. 1. The view of alumina nanofibers based materials before (a) and after (b) carbon deposition.

were slowly cooled to $150^{\circ} \mathrm{C}$ in the atmosphere of nitrogen. Typical view of alumina nanofibers based materials before and after carbon deposition is presented in Fig. 1.

\subsection{Materials characterization}

\subsubsection{Electron microscopy}

Scanning electron microscopy (SEM) and transmission electron microscopy (TEM) were used to confirm the formation of carbon structures on alumina nanofibers. SEM analysis was performed by the Hitachi scanning microscope S-5500 (Japan) operating at $3 \mathrm{kV}$. Before examination, the samples of Nafen nanofibers without carbon layer were coated with platinum by magnetron sputtering during $1 \mathrm{~min}$ at the current of $10 \mathrm{~mA}$ and the pressure of $8 \cdot 10^{-6} \mathrm{Bar}$ in argon atmosphere.

The TEM images were obtained by the Hitachi HT-7700 instrument (Japan) with an accelerating voltage of $100 \mathrm{kV}$. The samples were dispersed in ethanol by the ultrasonic homogenizer during 10 minutes at the power of $100 \mathrm{~W}$. The obtained dispersion was deposited on a carbon coated copper grid.

X-ray fluorescent microanalysis was conducted by combined energy dispersive X-ray spectrophotometer Quantax 70 with silicon drift detector (SDD) and energy resolution $154 \mathrm{eV}$ $(\mathrm{Cu}-\mathrm{K} \alpha)$.

\subsubsection{Nitrogen adsorption}

Low temperature nitrogen adsorption experiments were performed at ASAP-2420 (Micromeritics, USA) for pore and surface area characterizations. Samples were loaded in the 
calibrated measure tubes and outgased (prepared for analysis) for 6-8 hours at $150-200{ }^{\circ} \mathrm{C}$ under vacuum of 6-10 $\mu \mathrm{m} \mathrm{Hg}$. After sample mass correction, tubes were transferred to analysis schematic for isotherm registration. Warm and cold free spaces of sample tubes with loaded samples were measured before analysis. Relative pressure $\left(\mathrm{P} / \mathrm{P}_{0}\right)$ range was $0-0.99$. Measure gas was dosed in an incremental mode. The dose increment was $2 \mathrm{~cm}^{3} \mathrm{~g}^{-1}$ for $\mathrm{P} / \mathrm{P}_{0}$ range $0-0.001$, while it was $10 \mathrm{~cm}^{3} \mathrm{~g}^{-1}$ for $\mathrm{P} / \mathrm{P}_{0}$ from 0.001 up to 0.995 . Equilibration interval was equal to 40 seconds. Nitrogen saturation pressure was measured at every isotherm point to calculate $\mathrm{P}_{0}$ and analysis bath temperature. Textural characteristics calculations of materials under consideration were realized with BET, BJH, and t-plot models. Correlation coefficient for BET transform plot was not less than 0.999. Fitted thickness range for $\mathrm{t}-$ plot calculations was 3.5-5.0 $\AA$. Thickness equation for $\mathrm{t}-$ plot and $\mathrm{BJH}$ method is (Harkins and Jura):

$$
t=\sqrt{\frac{13.99}{0.034-\log \left(P / P_{0}\right)}} .
$$

\subsubsection{Spectroscopy}

The structure of the formed carbon layers was determined by the Raman spectroscopy. Raman spectra in the backscattering geometry were recorded with the Centaur U HR setup equipped with a Raman spectrometer with a high spectral resolution due to the use of a double dispersion monochromator. Nd:YAG laser with $\lambda=532 \mathrm{~nm}$ and power $1 \mathrm{~mW}$ on a sample was used as an excitation light source.

X-ray photoelectron spectra were measured with a SPECS instrument equipped with a PHOIBOS 150 MCD 9 hemispherical analyzer at electron take-off angle 900 with the pass energy of $10 \mathrm{eV}$ for high-resolution spectra and $20 \mathrm{eV}$ for survey spectra. The spectra were excited by monochromatic $\mathrm{Al} \mathrm{K \alpha}$ irradiation $(1486.6 \mathrm{eV})$ of an X-ray tube. The pressure in an analytical chamber was in the range of $10^{-9} \mathrm{mBar}$. The $\mathrm{C}$ 1s spectra were fitted with Gaussian-Lorentzian peak profiles after subtraction of a Shirley-type background utilizing the CasaXPS software package.

\subsubsection{Thermal analysis}

To study the influence of synthesis time on the amount of deposited carbon and properties of carbon layers, synchronous thermal analysis was used. Thermal analysis of carbon coated samples was performed on NETZCH Jupiter 449 with mass-spectrometer detector. A sample was crushed with the pestle and mortar. After that, it was placed into Pt melting pot on the differential 
sensor with identical Pt melting pot as a reference and then heated in the oven unit in the air up to $1200{ }^{\circ} \mathrm{C}$.

\subsubsection{Measurement of electrical resistance}

In order to measure electrical resistance of conductive carbon layers formed on Nafen alumina nanofibers, we employed the Four Probe DC method. The pieces of carbon coated alumina nanofiber materials (see Fig. 1 (c)) were used for measurements. Four metal tips (electrodes) located along the same line were attached to the sample surface. This step is necessary to establish a reliable electrical contact between the probe and the surface. The distance between the tips was $1 \mathrm{~mm}$. Current was supplied through the external electrodes and the voltage drop between the inner electrodes was recorded with the help of potentiostat/galvanostat PI50-Pro (ELINS Ltd., Russia). The resistance of surface layers was calculated from the slope of volt-ampere curve.

\section{Results and discussion}

\subsection{Morphology of carbon-coated alumina nanofibers}

To understand the morphological changes in Nafen based materials after deposition of carbon, electron microscopy methods were used. SEM images show no significant differences between alumina nanofibers before (Fig. 2a) and after (Fig. 2b) deposition of carbon. In order to understand how thickness of forming carbon layer depends on the CVD synthesis time, we have performed a comparative analysis of TEM images for Nafen fibers with different synthesis times (from $0 \mathrm{~s}$ to $600 \mathrm{~s}$ ). In the absence of carbon coating, a typical TEM images (Fig. 3, $0 \mathrm{~s}$ ) shows that the average fiber diameter in the Nafen material is around $10 \mathrm{~nm}$, which agrees with the information provided by the manufacturer [31]. After deposition of carbon (Fig. 3, $60-600 \mathrm{~s}$ ), a multilayered carbon structure is formed on the surface of alumina nanofibers. It can also be seen that carbon layer differs on different parts of nanofibers, so to estimate the thickness of carbon layers the statistical analysis of TEM images was performed. The results provided in Table 1 show that the average thickness of carbon layer increases by more than two times with increasing the CVD synthesis time from 60 to $600 \mathrm{~s}$. It is accompanied by the corresponding decrease of total pore volume calculated from low-temperature nitrogen adsorption data. The nonlinear decrease of

pore volume and surface area is obviously associated with the intrinsic porous structure of the deposited carbon, but in general still correlates with the increase of carbon layers thickness. 
Table 1. Pore volume and surface area characteristics of samples obtained with different CVD synthesis times. Carbon layer thickness is obtained from statistical analysis of TEM images.

\begin{tabular}{|c|c|c|c|}
\hline $\begin{array}{c}\text { Synthesis time, } \\
\mathrm{s}\end{array}$ & $\begin{array}{c}\text { Total pore } \\
\text { volume }, \mathrm{cm}^{3} / \mathrm{g}\end{array}$ & $\begin{array}{c}\text { Specific surface } \\
\text { area, } \mathrm{m}^{2} / \mathrm{g}\end{array}$ & Carbon layer thickness, $\mathrm{nm}$ \\
\hline 60 & 0.565 & 103 & $1.05 \pm 0.26$ \\
\hline 120 & 0.554 & 114 & $1.45 \pm 0.44$ \\
\hline 300 & 0.507 & 113 & $1.59 \pm 0.57$ \\
\hline 600 & 0.372 & 95 & $2.18 \pm 0.89$ \\
\hline
\end{tabular}

As it was previously shown [37], the $60 \mathrm{~s}$ deposition of carbon on the surface of alumina nanofibers in the selected CVD conditions led to uniform carbon distribution along the entire cross-section of alumina disc. The X-ray fluorescence analysis of carbon coated discs was also used here to confirm the preservation of uniform carbon distribution with increasing time of CVD synthesis.

Figure $4 \mathrm{a}$ and $4 \mathrm{~b}$ show the SEM images of discs cross-sections for 60 and 600 seconds of CVD, while the corresponding X-ray carbon distribution maps are provided in Fig. $4 \mathrm{c}$ and $4 \mathrm{~d}$. The formation of carbon structures in the entire thickness of the discs is observed. The increase of the area under the carbon peak (Fig. 4d) indirectly confirms the conclusion about increasing of carbon amount with increasing the CVD synthesis time.
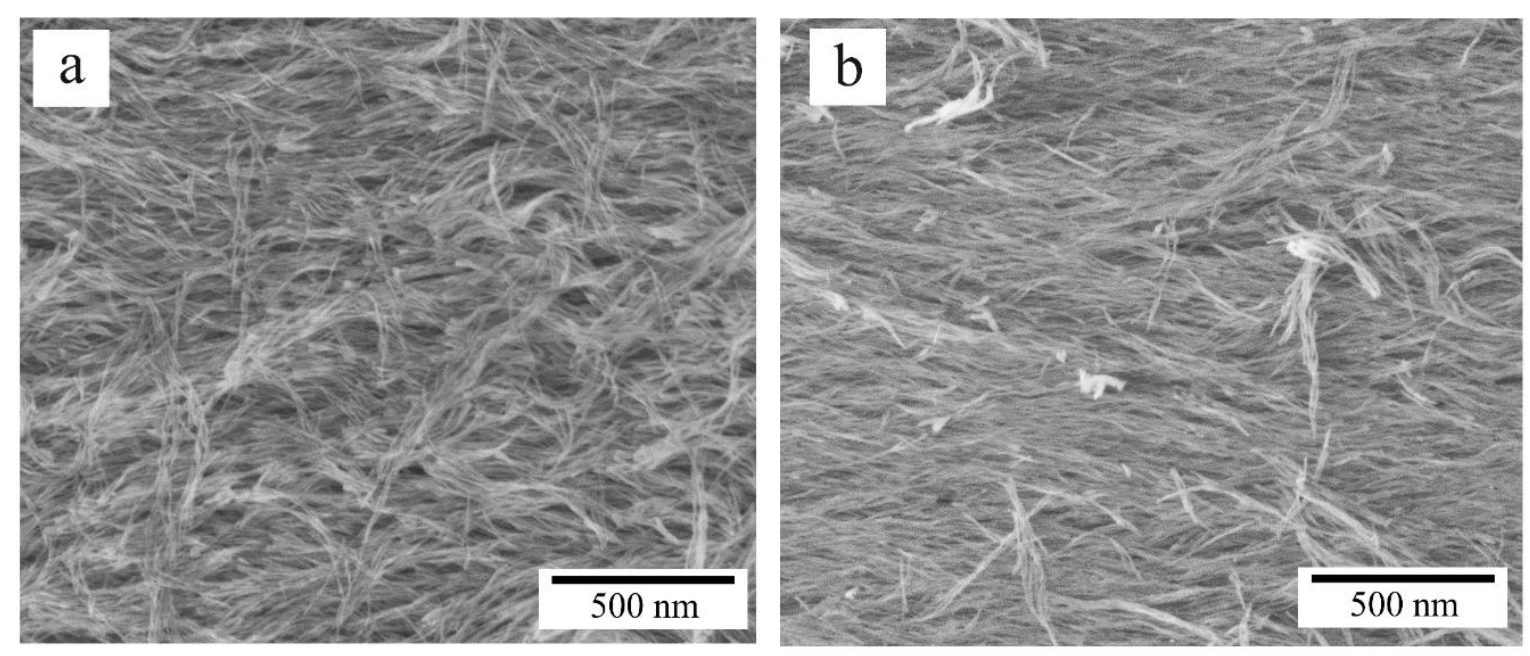

Fig. 2. SEM images of Nafen fibers before (a) and after (b) deposition of carbon. The corresponding TEM images of nanofibers are shown in the insets. 

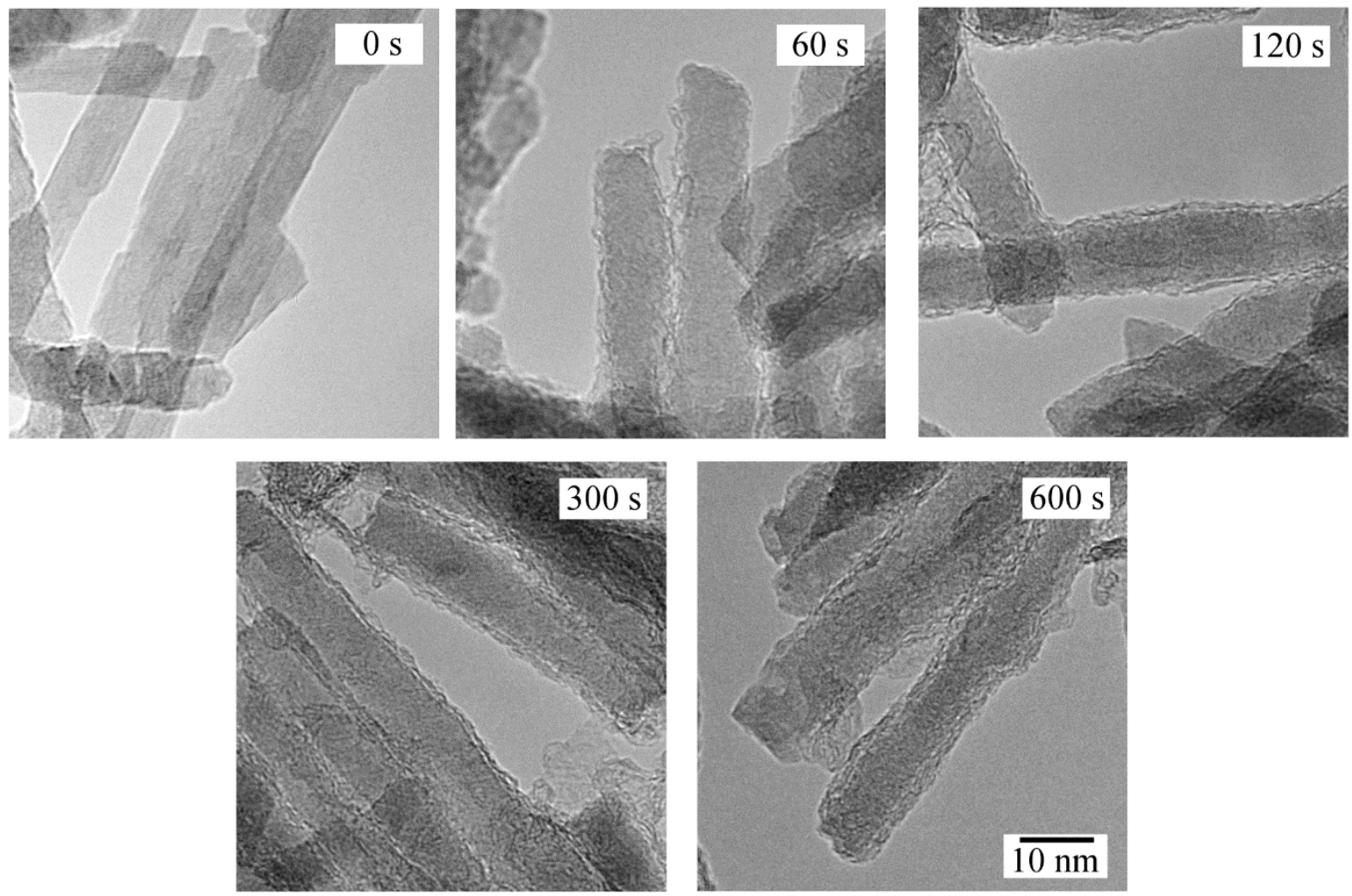

Fig. 3. TEM images of Nafen fibers before $(0 \mathrm{~s})$ after deposition of carbon with different CVD synthesis times (60, 120, 300, $600 \mathrm{~s})$.

\subsection{Thermal analysis of carbon-coated Nafen based materials}

Typical thermal analysis data of carbon coated alumina nanofibers (further $\mathrm{C} / \mathrm{Al}_{2} \mathrm{O}_{3}$ ) is shown in Fig. 5. According to the TGA and mass-spectra of volatile pyrolysis products, for $\mathrm{C} / \mathrm{Al}_{2} \mathrm{O}_{3}$ obtained for $\mathrm{CVD}$ time of $60 \mathrm{~s}$, the first weight loss of $11.5 \%$ occurs up to $230{ }^{\circ} \mathrm{C}$ and corresponds to water evaporation.

Comparison of thermal analysis data with the results of differential scanning calorimetry shows the two stages of combustion of carbon layers on Nafen fibers (Figs. 5, 6). The first stage results in wide peak of weight loss at $230-460{ }^{\circ} \mathrm{C}$ accompanied by exothermic thermal effect (peak on DSC about $230{ }^{\circ} \mathrm{C}$ ) and $\mathrm{CO}_{2}$ evolution (the total mass loss is $4.5 \%$ ), the second one takes place at $586.8^{\circ} \mathrm{C}$ with thermal effect of $3.36 \mathrm{~kJ} / \mathrm{g}$ and intensive $\mathrm{CO}_{2}$ evolution. Intensive mass loss at $250-300{ }^{\circ} \mathrm{C}$ is observed due to release of functional groups. The total mass loss at these stages is $15.1 \%$, which agrees with the direct measurements during synthesis.

Results of thermal analysis and calorimetry indicate different behavior of $\mathrm{C} / \mathrm{Al}_{2} \mathrm{O}_{3}$ obtained by CVD with different synthesis time when heated in an air atmosphere (Fig. 7). 

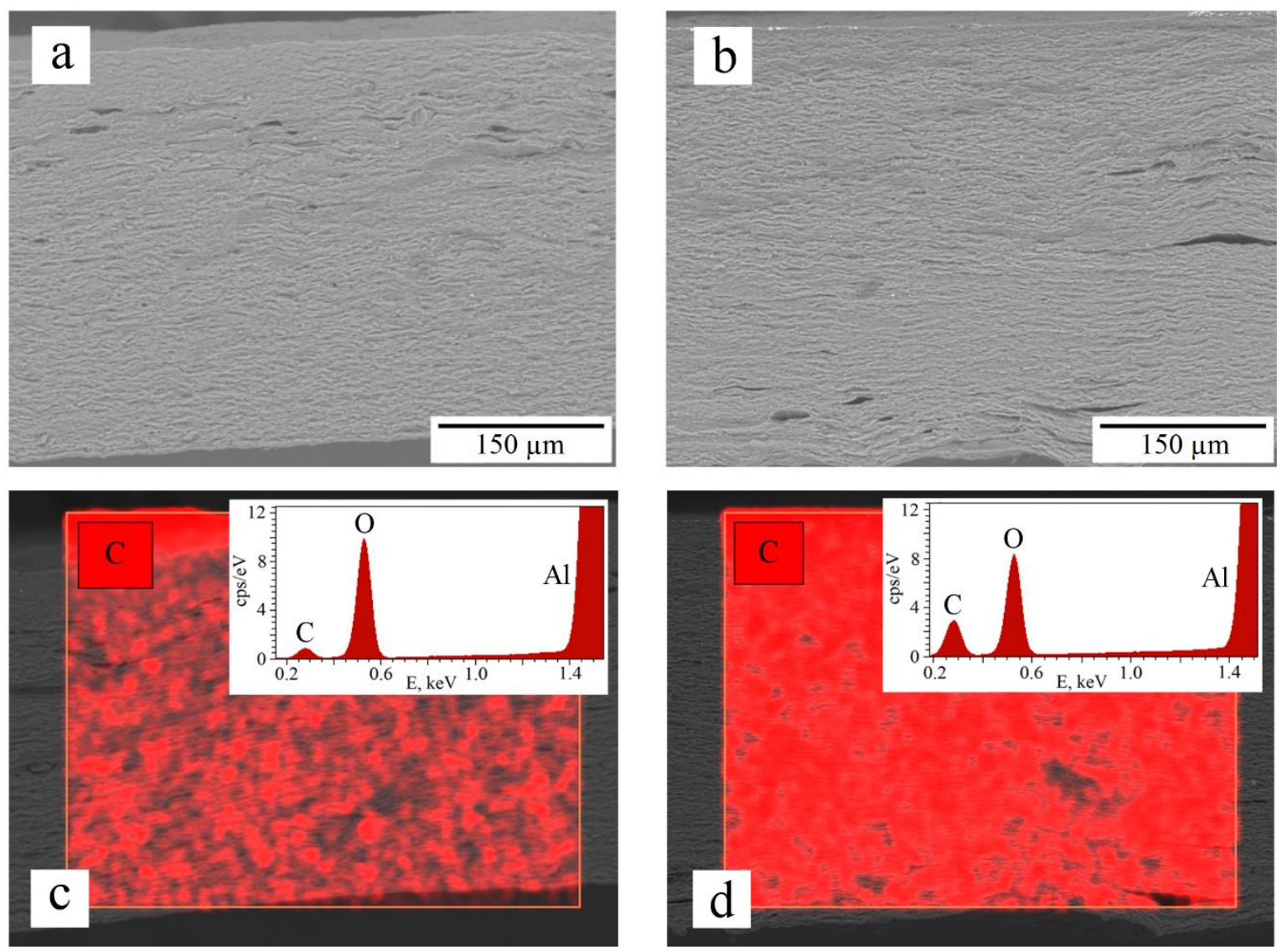

Fig. 4. SEM images (a, b) and carbon distribution X-ray maps (c, d) of cross-sections of carbon coated alumina discs: a, c - for 60 s of CVD; b, d - for $600 \mathrm{~s}$ of CVD.

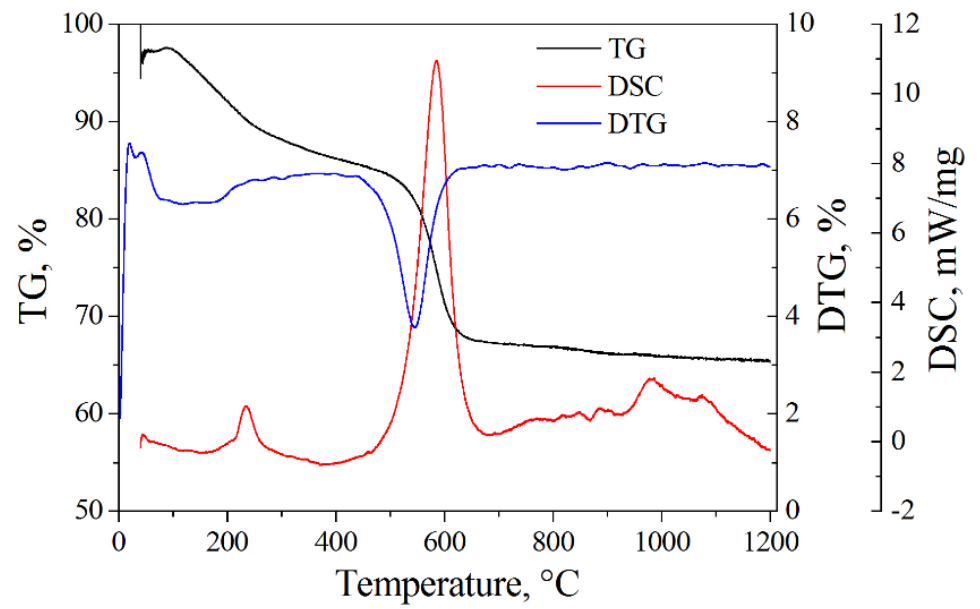

Fig. 5. Thermal analysis data for $\mathrm{C} / \mathrm{Al}_{2} \mathrm{O}_{3}$ obtained for $60 \mathrm{~s}$ of CVD [37]. 

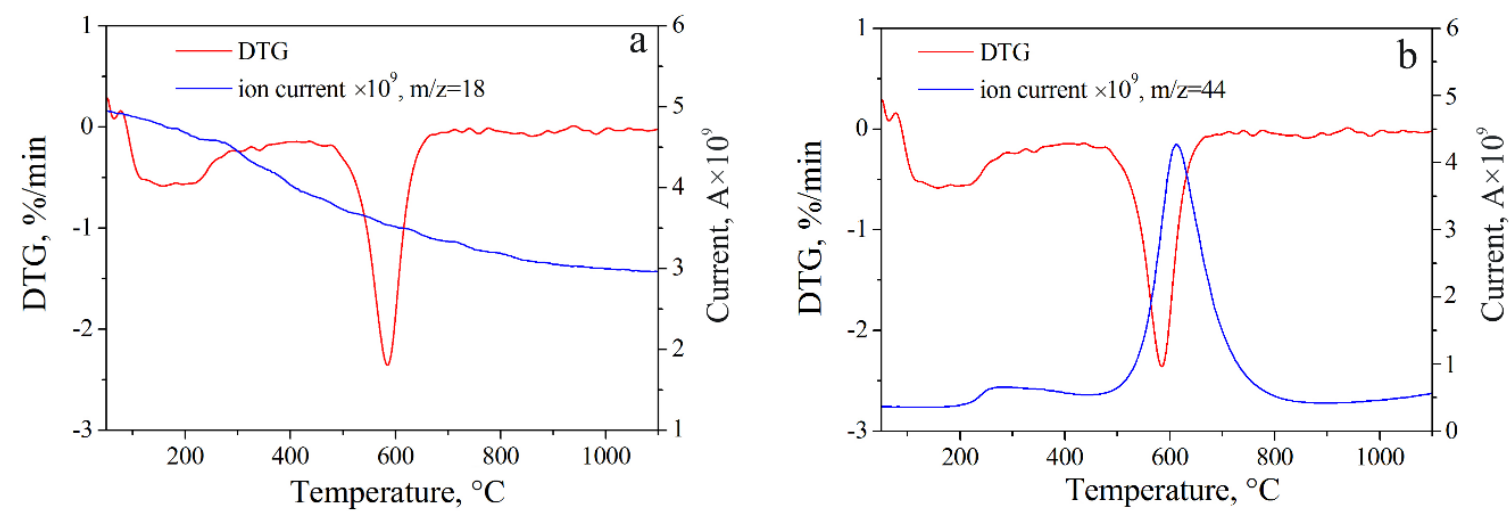

Fig. 6. Mass-spectra of volatile pyrolysis products for $\mathrm{C} / \mathrm{Al}_{2} \mathrm{O}_{3}$ with $60 \mathrm{~s}$ of CVD:

(a) $\mathrm{m} / \mathrm{z}=18\left(\mathrm{H}_{2} \mathrm{O}\right),(\mathrm{b}) \mathrm{m} / \mathrm{z}=44\left(\mathrm{CO}_{2}\right)$.

Comparison of thermal analysis data with the results of the differential scanning calorimetry indicates the disappearance of water evaporation stage and the early carbon combustion stage with increasing of synthesis time up to $300 \mathrm{~s}$. The maximum of mass loss shifts to a higher temperature region (from 580 to $660^{\circ} \mathrm{C}$ ) with the corresponding shift of thermal effect that confirms a later start of carbon combustion (Fig. 7).

Based on the results of thermal analysis, the average content of obtained materials can be estimated (Table 2). The amount of carbon is determined from the mass loss during the carbon combustion state, while the amount of $\mathrm{Al}_{2} \mathrm{O}_{3}$ corresponds to the mass of non-combustible residue after the thermal analysis. The thermal effect was calculated based on the area below the DSC curve plotted as a function of time in the standard Proteus Netzch software package. The combustion temperature corresponds to the position of peak maximum on the DSC curve.

It can be seen that the increase of synthesis time increases the amount of carbon on alumina surface. The sharp increase in carbon quantity at $300 \mathrm{~s}$ in comparison with $120 \mathrm{~s}$ can be associated with the filling of pore system by growing carbon. Once the inner pores are filled, carbon continues to grow mainly on the sample surface resulting in further increase on carbon fraction.

According to the data in Table 2, the combustion temperature increases with increasing the CVD synthesis time. The sample corresponding to $120 \mathrm{~s}$ is an exception from the general trend. A slight decrease of combustion temperature with increasing the synthesis time from $60 \mathrm{~s}$ to $120 \mathrm{~s}$ can be explained by a larger specific surface area of the latter sample (see Table 1). 

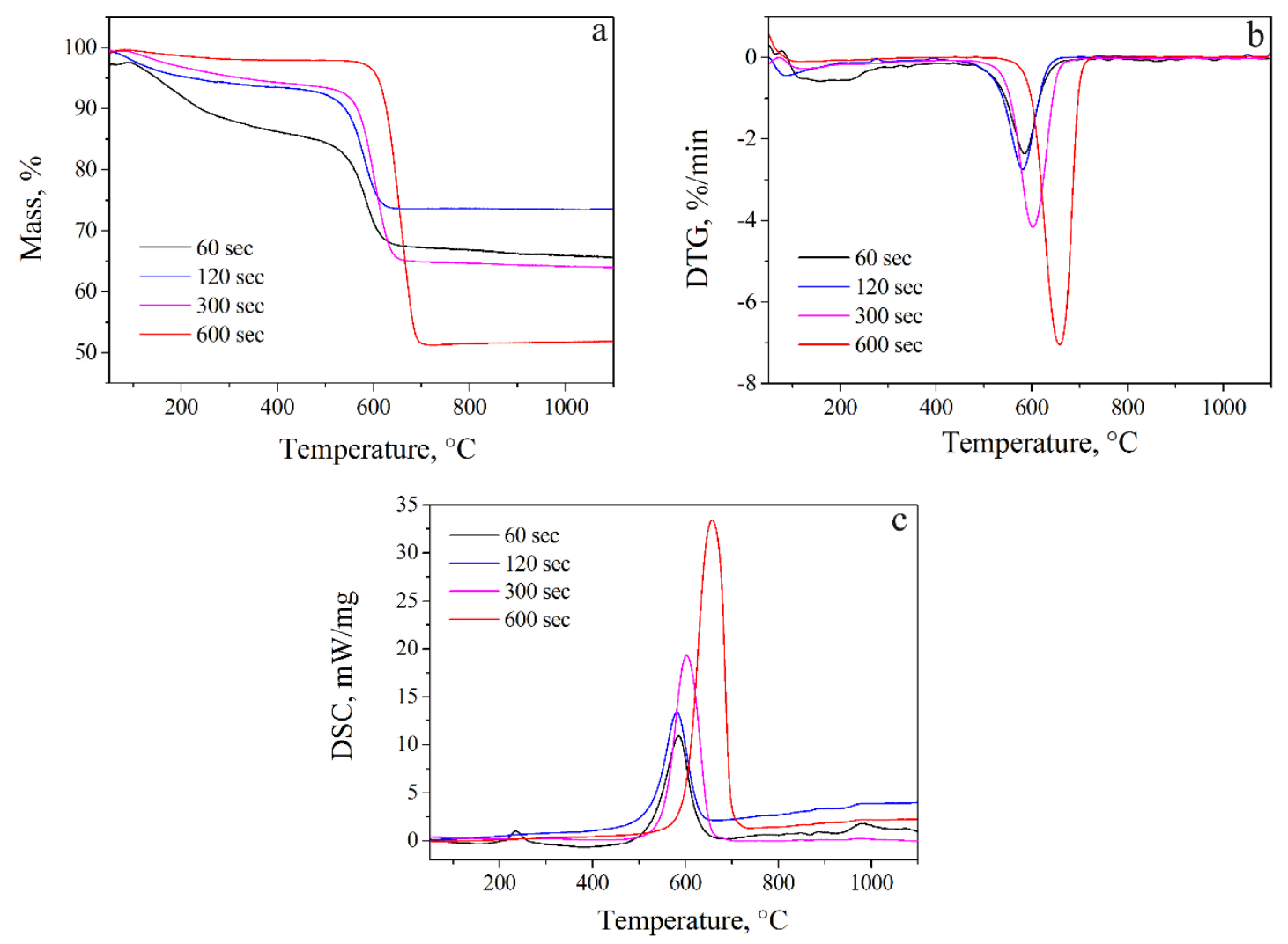

Fig. 7. Thermal analysis data for $\mathrm{C} / \mathrm{Al}_{2} \mathrm{O}_{3}$ obtained by CVD with different synthesis time: (a) thermal data, (b) differential thermal analysis, (c) differential scanning calorimetry.

Table 2. Summary data of thermal analysis of carbon on $\mathrm{Al}_{2} \mathrm{O}_{3}$ obtained for different CVD synthesis times.

\begin{tabular}{|c|c|c|c|c|}
\hline $\begin{array}{c}\text { Synthesis time, } \\
\mathrm{s}\end{array}$ & $\begin{array}{c}\text { Mass fraction of } \\
\mathrm{Al}_{2} \mathrm{O}_{3}\end{array}$ & $\begin{array}{c}\text { Mass fraction } \\
\text { of carbon }\end{array}$ & $\begin{array}{c}\mathrm{Q}, \\
\mathrm{kJ} / \mathrm{g}\end{array}$ & $\begin{array}{c}\text { Combustion } \\
\text { temperature, }{ }^{\circ} \mathrm{C}\end{array}$ \\
\hline 60 & 0.676 & 0.174 & 3.36 & 586.8 \\
\hline 120 & 0.736 & 0.193 & 4.58 & 581.1 \\
\hline 300 & 0.64 & 0.287 & 7.55 & 602.5 \\
\hline 600 & 0.519 & 0.464 & 12.8 & 657.3 \\
\hline
\end{tabular}

\subsection{XPS spectroscopy}

Early carbon combustion stage observed for the $\mathrm{C} / \mathrm{Al}_{2} \mathrm{O}_{3}$ obtained in $60 \mathrm{~s}$ of CVD (Fig.5, 6) can be explained by burnout of defects and functional groups with heteroatoms that can be formed on the carbon surface during CVD process. For example, oxygen-containing groups may occur due to partial surface oxidation by air oxygen. This assumption was partly confirmed by 


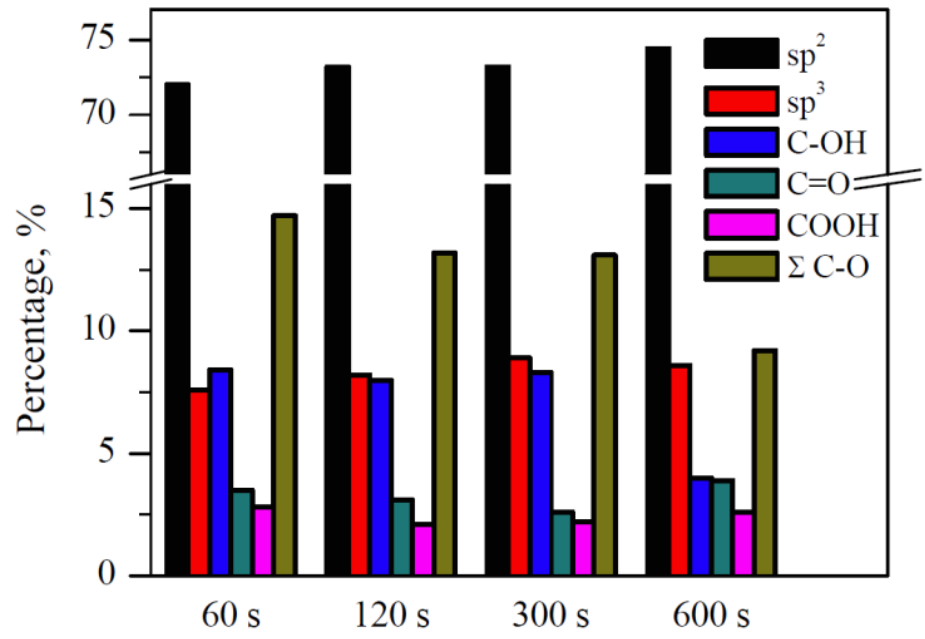

Fig. 8. The results of fitting of the photoelectron $\mathrm{C} 1 \mathrm{~s}$ spectra for $\mathrm{C} / \mathrm{Al}_{2} \mathrm{O}_{3}$ composites prepared at different CVD synthesis times.

previously described results of IR spectroscopy [37]. After deposition of carbon for $60 \mathrm{~s}$ of CVD, the peaks characterizing the presence of $\mathrm{C}=\mathrm{C}$ bond $\left(1580 \mathrm{~cm}^{-1}\right)$ and $\mathrm{C}=\mathrm{O}$ bond $\left(1236 \mathrm{~cm}^{-1}\right)$ appeared.

The TGA data reveal the disappearance of early (up to $300^{\circ} \mathrm{C}$ ) carbon combustion stage for materials obtained after more than $120 \mathrm{~s}$ of CVD (Fig 7). It can be caused by a decrease of functional groups and defects in forming carbon layers. To confirm this assumption, the $\mathrm{C} / \mathrm{Al}_{2} \mathrm{O}_{3}$ obtained after different times of CVD synthesis was studied by X-ray photoelectron spectroscopy (XPS). The results of fitting the $\mathrm{C} 1 \mathrm{~s}$ spectra using typical set of carbon species, i.e., graphite at the binding energy of $284.45 \mathrm{eV}$, aliphatic carbon $(285-285.5 \mathrm{eV})$, alcohol groups $(286.1-286.5$ $\mathrm{eV}$ ), carbonyl groups (about $267.5 \mathrm{eV}$ ), and carboxylic groups $(288.5-288.9 \mathrm{eV})$ are shown in Fig. 8. The X-ray photoelectron survey and C 1s spectra can be found in the Supplement Info (Fig. S1).

XPS data show that the concentration of oxygen-bearing functional groups is highest for the $\mathrm{C} / \mathrm{Al}_{2} \mathrm{O}_{3}$ obtained in $60 \mathrm{~s} \mathrm{CVD}$, and decreases with increasing the CVD synthesis time. This may be related, in particular, with enhancing temperature of carbon combustion at TG curves on Fig. 7. The lower content of surface functional groups and the later start of carbon combustion with the increase of synthesis time can be also interpreted in terms of an increase in the ordering of carbon. It agrees with currently existing ideas about the formation of more ordered carbon structures at elevated temperatures [42]. 


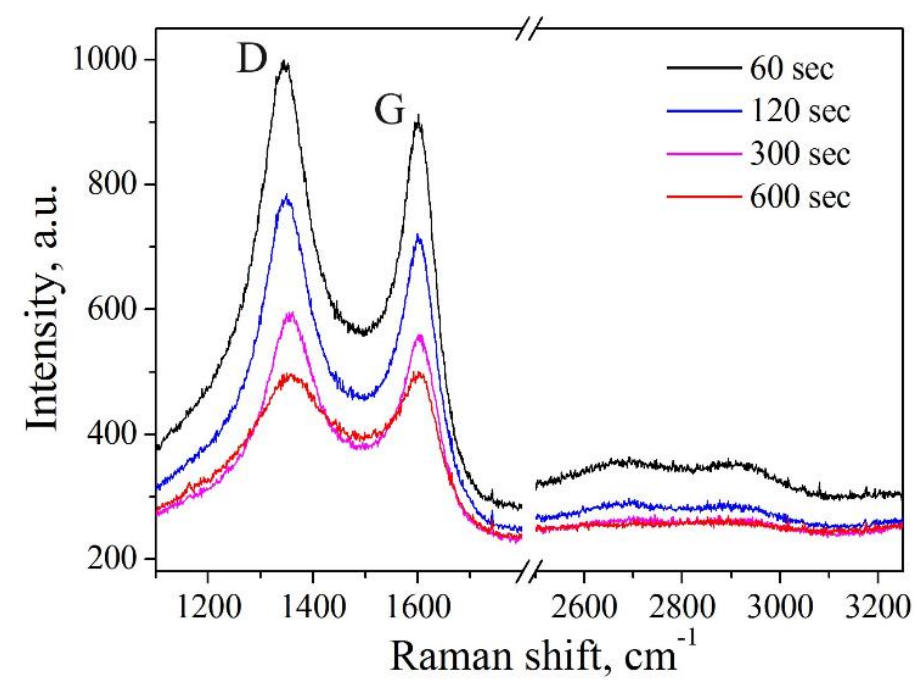

Fig. 9. Raman spectra of $\mathrm{C} / \mathrm{Al}_{2} \mathrm{O}_{3}$ obtained by $\mathrm{CVD}$ with different synthesis time.

The relative intensity $\mathrm{I}_{\mathrm{D}} / \mathrm{I}_{\mathrm{G}}$ is $1.12,1.11,1.09,0.99$ for $60,120,300,600 \mathrm{~s}$ of CVD synthesis time, respectively.

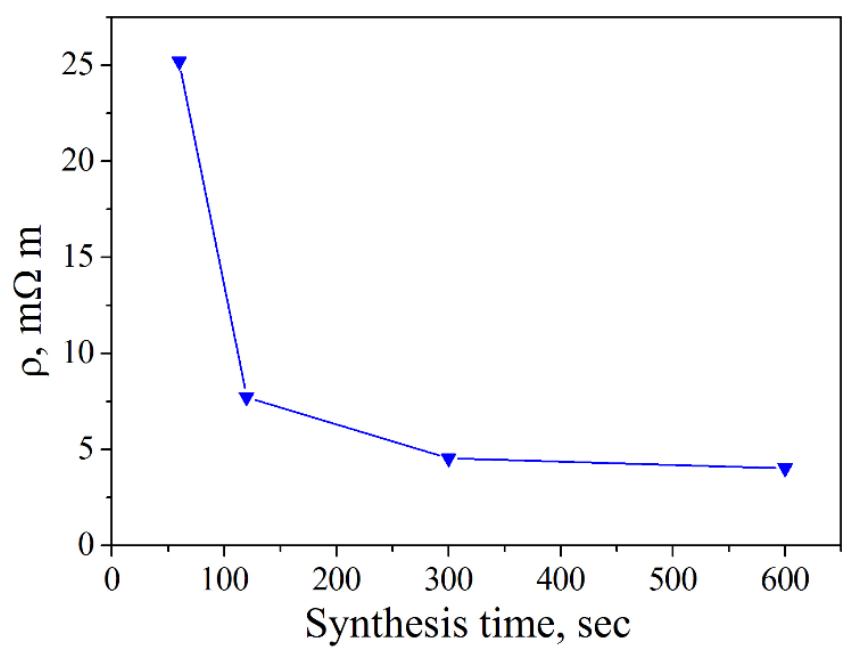

Fig. 10. The dependence of carbon layer resistance on the CVD synthesis time.

\subsection{Raman spectroscopy}

To provide an additional confirmation for the increase of carbon ordering at higher synthesis temperatures, the Raman spectroscopy was used. It is known as an effective instrument for characterization carbon materials obtained by CVD [43]. Raman spectra for materials obtained during different synthesis times are shown at the Fig. 9. The obtained data clearly show the formation of disordered carbon structures in all cases: the peaks at $1350 \mathrm{~cm}^{-1}$ and $1600 \mathrm{~cm}^{-1}$ correspond to the $\mathrm{D}$ (disorder) and $\mathrm{G}$ (graphitic) peaks of the carbon. When increasing the synthesis time from 60 to 600 seconds, the corresponding decrease of relative intensity of D and 
G peaks $\left(\mathrm{I}_{\mathrm{D}} / \mathrm{I}_{\mathrm{G}}\right)$ is observed (see Fig. 9). It indicates the reduction of defects in carbon layers for higher synthesis times.

\subsection{Electrical resistance}

In Figure 10, we show the dependence of resistance for carbon-coated Nafen based materials on the synthesis time. It can be seen that increasing this time from $60 \mathrm{~s}$ to $600 \mathrm{~s}$ results in the decrease of resistance from 25 to $4 \mathrm{~m} \Omega \cdot \mathrm{m}$. It provides an additional confirmation of the increase of carbon structure thickness, interconnectivity, and ordering with increasing the CVD synthesis time. The lower resistance could be considered as an indirect confirmation of the reduction of defects in carbon structure $[44,45]$.

\section{Conclusion}

We have prepared a composite alumina-carbon material by non-catalytic metal-free chemical vapor deposition of propane on Nafen alumina nanofibers. According to SEM and TEM results, this process leads to the formation of multilayered carbon on the surface of alumina nanofibers. The average thickness of carbon layer increases by more than two times (up to 2-3 $\mathrm{nm}$ ) with the increase of CVD synthesis time from 60 to 600 seconds. X-ray carbon distribution maps confirm the increase of carbon amount for larger synthesis times.

According to mass spectra of volatile pyrolysis products and XPS analysis, the obtained carbon structures contain alcohol, carboxyl and carbonyl functional groups for all studied CVD synthesis times. The XPS analysis reveals the decrease of oxygen-containing groups concentration with the increase of synthesis time.

The thermal analysis shows that the peak of carbon combustion shifts to a higher temperature region indicating the increase of carbon ordering. Raman spectroscopy and measurement of electrical resistance confirm this conclusion. These findings could be employed for further development of conductive nanoporous membranes for switchable ion transport $[36,37,40]$ as well electroconductive ceramics $[33,34]$.

\section{Acknowledgement}

The work is supported by the Russian Foundation for Basic Research Grant № 18-2919078. The physicochemical analysis of materials was carried out on equipment of Krasnoyarsk Scientific Center of Shared Facilities SB RAS. 


\section{References}

1. Y. Xu, X.-T. Yan Chemical vapour deposition. An integrated engineering design for advanced materials, Springer-Verlag London Limited, 2010. http://dx.doi.org/10.1007/978-1$\underline{84882-894-0}$

2. N. Tripathi, P. Mishra, B. Joshi Catalyst free, excellent quality and narrow diameter of CNT growth on Al2O3 by a thermal CVD technique. Physica E 62 (2014) 43-47 http://dx.doi.org/10.1016/j.physe.2014.04.011

3. Y. Sun, R. Kitaura, J. Zhang, et al Metal catalyst-free mist flow chemical vapor deposition growth of single-wall carbon nanotubes using C60 colloidal solutions Carbon 68 (2014) 80 - 86 http://dx.doi.org/10.1016/j.carbon.2013.10.038

4. J. Sun, F. Dillon, C. Wu, et al Metal-free chemical vapor deposition growth of graphitic tubular structures on engineered perovskite oxide substrates Carbon 99 (2016) 591 - 598 http://dx.doi.org/10.1016/j.carbon.2015.12.084

5. M. Alsawat, T. Altalhi, K. Gulati, et al, Synthesis of carbon nanotubes-nanotubular titania composites by catalyst-free CVD process: insights into the formation mechanism and photocatalytic properties ACS Appl. Mater. Interfaces 7 (2015) 28361-28368 http://dx.doi.org/10.1021/acsami.5b08956

6. P. Ciambelli, L. Arurault, M. Sarno, et al, Controlled growth of CNT in mesoporous AAO through optimized conditions for membrane preparation and CVD operation Nanotechnology 22 (2011) 265613 http://dx.doi.org/10.1088/0957-4484/22/26/265613

7. M. Alsawat, T. Altalhi, A. Santos, et al Carbon nanotubes-nanoporous anodic alumina composite membranes: influence of template on structural, chemical and transport properties J. Phys. Chem. C, 121 (2017) 13634-13644 http://dx.doi.org/10.1021/acs.jpcc.7b01257

8. M. Hiramatsu, K. Shiji, H. Amano, et al Fabrication of vertically aligned carbon nanowalls using capacitively coupled plasma-enhanced chemical vapor de position assisted by hydrogen radical injection Applied Physics Letters $84 \quad$ (2004) 4708 http://dx.doi.org/10.1063/1.1762702

9. S. Moitzheim, C. S. Nimisha, S. Deng et al, Nanostructured TiO2/carbon nanosheet hybrid electrode for high-rate thin-film lithium-ion batteries, Nanotechnology 25 (2014) 504008 http://dx.doi.org/10.1088/0957-4484/25/50/504008

10. I.S. Hosu, M. Sobaszek, M. Ficek, et al, Carbon nanowalls: A new versatile graphene based interface for laser desorption/ionization-mass spectrometry detection of small compounds in real samples. Nanoscale, 2017, http://dx.doi.org/10.1039/C7NR01069A 
11. H. Wang and G. Yu Direct CVD graphene growth on semiconductors and dielectrics for transfer-free device fabrication Adv. Mater. 28 (2016) 4956-4975 http://dx.doi.org/10.1002/adma.201505123

12. J. Chen, Y. Guo, L. Jiang, et al, Near-equilibrium chemical vapor deposition of high-quality single-crystal graphene directly on various dielectric substrates Adv. Mater. 26 (2014) 1348-1353 http://dx.doi.org/10.1002/adma.201304872

13. C.Y. Chen, D. Dai, G.X. Chen, et al Rapid growth of single-layer graphene on the insulating substrates by thermal CVD. Applied Surface Science 346 (2015) 41-45 http://dx.doi.org/10.1016/j.apsusc.2015.03.204

14. J. Pang, A. Bachmatiuk, I. Ibrahim, et al, CVD growth of 1D and 2D sp2 carbon nanomaterials, J Mater Sci. 51 (2016) 640-667 http://dx.doi.org/10.1007/s10853-015-9440-z

15. J. Sun, M. T. Cole, N. Lindvall, et al Noncatalytic chemical vapor deposition of graphene on high-temperature substrates for transparent electrodes Appl Phys Lett 100 (2012) 022102 http://dx.doi.org/10.1063/1.3675632

16. S. Chugh, R. Mehta, N. Lu, et al Comparison of graphene growth on arbitrary noncatalytic substrates using low-temperature PECVD Carbon $93 \quad$ (2015) 393 - 399 http://dx.doi.org/10.1016/j.carbon.2015.05.035

17. R. Munoz, C. Gomez-Aleixandre Fast and non-catalytic growth of transparent and conductive graphene-like carbon films on glass at low temperature J. Phys. D: Appl. Phys. 47 (2014) 045305 http://dx.doi.org/10.1088/0022-3727/47/4/045305

18. Y.B. Chen, J.Y. Sun, J.F. Gao, et al., Growing uniform graphene disks and films on molten glass for heating devices and cell culture, Adv. Mater. 27 (2015) 7839 - 7846 http://dx.doi.org/10.1002/adma.201504229

19. Y. S. Kim, K. Joo, S. Jerng, et al, Direct growth of patterned graphene on $\mathrm{SiO} 2$ substrates without the use of catalysts or lithography Nanoscale 6 (2014) 10100-10105 http://dx.doi.org/10.1039/C4NR02001D

20. A. Scott, A. Dianat, F. Borrnert, et al, The catalytic potential of high-kappa dielectrics for graphene formation Appl. Phys. Lett 98 (2011) 073110 http://dx.doi.org/10.1063/1.3556639

21. J. Sun, N. Lindvall, M. T. Cole, et al, Large-area uniform graphene-like thin films grown by chemical vapor deposition directly on silicon nitride Appl Phys Lett 98 (2011) 252107 http://dx.doi.org/10.1063/1.3602921

22. M. Lukosius, J. Dabrowski, J. Kitzmann, et al Metal-free CVD Graphene synthesis on $200 \mathrm{~mm}$ Ge/Si (100) substrates ACS Appl. Mater. Interfaces, 8 (2016) 33786-33793 http://dx.doi.org/10.1021/acsami.6b11397 
23. S. K. Jerng, D. S. Yu, Y. S. Kim, et al Nanocrystalline graphite growth on sapphire by carbon molecular beam epitaxy J Phys Chem C 115 (2011) 4491-4494 http://dx.doi.org/10.1021/jp110650d

24. D. Wei, L. Peng, M. Li, et al Low temperature critical growth of high quality nitrogen doped graphene on dielectrics by plasma-enhanced chemical vapor deposition ACS Nano 9 (2015) 164-171 http://dx.doi.org/10.1021/nn505214f

25. J. Park, J. Lee, J. H. Choi, et al Direct fabrication of 3D graphene on nanoporous anodic alumina by plasma-enhanced chemical vapor deposition Sci Rep. 6 (2016) 19822 http://dx.doi.org/10.1038/srep19822

26. L. Zhang, Z. Shi, Y. Wang, et al Catalyst-free growth of nanographene films on various substrates Nano Res. 4 (2011) 315-321 http://dx.doi.org/10.1007/s12274-010-0086-5

27. J. Hwang, M. Kim, D. Campbell, et al, van der Waals epitaxial growth of graphene on sapphire by chemical vapor deposition without a metal catalyst ACS Nano 7 (2013) 385-395 http://dx.doi.org/10.1021/nn305486x

28. H. J. Song, M. Son, C. Park, et al Large scale metal-free synthesis of graphene on sapphire and transfer-free device fabrication Nanoscale 4 (2012) 3050-3054 http://dx.doi.org/10.1039/c2nr30330b

29. N.-E. Weber, A. Binder, M. Kettner, et al, Metal-free synthesis of nanocrystalline graphene on insulating substrates by carbon dioxide-assisted chemical vapor deposition Carbon 112 (2017) 201 - 207 http://dx.doi.org/10.1016/j.carbon.2016.11.007

30. S. Zheng, G.-F. Zhong, X.-Y. Wu, et al Metal-catalyst-free growth of graphene on insulating substrates by ammonia-assisted microwave plasma-enhanced chemical vapor deposition RSC Adv. 7 (2017) 33185-33193 http://dx.doi.org/10.1039/c7ra04162d

31. Features of Nafen alumina nanofibers, http://www.anftechnology.com/nafen/

32. M. Aghayan, I. Hussainova, M. Gasik, et al, Coupled thermal analysis of novel alumina nanofibers with ultrahigh aspect ratio, Thermochim Acta 574 (2013) 140-144 $\underline{\text { http://dx.doi.org/10.1016/j.tca.2013.10.010 }}$

33. I. Hussainova, R. Ivanov R, S. M. Stamatin, et al A few-layered graphene on alumina nanofibers for electrochemical energy conversion, Carbon 88 (2015) 157-164 http://dx.doi.org/10.1016/j.carbon.2015.03.004

34. M. Drozdova, I. Hussainova, D. Pérez-Coll, et al, A novel approach to electroconductive ceramics filled by graphene covered nanofibers, Materials and Design, 90 (2016) 291-298 http://dx.doi.org/10.1016/j.matdes.2015.10.148 
35. M. Taleb, R. Ivanov, S. Bereznev, et al, Graphene-ceramic hybrid nanofibers for ultrasensitive electrochemical determination of ascorbic acid, Microchim Acta, 184 (2017) 897 905 http://dx.doi.org/10.1007/s00604-017-2085-7

36. D. V. Lebedev, A. V. Shiverskiy, M. M. Simunin, et al, Preparation and ionic selectivity of carbon-coated alumina nanofiber membranes, Petroleum Chemistry, 57 (2017) 306-317 http://dx.doi.org/10.1134/S096554411704003X

37. V. S. Solodovnichenko, D. V. Lebedev, V. V. Bykanova, et al. Carbon coated alumina nanofiber membranes for selective ion transport, Adv. Eng. Mater. 2017, 1700244 http://dx.doi.org/10.1002/adem.201700244

38. Ryzhkov I.I., Lebedev D.V., Solodovnichenko V.S., Shiverskiy A.V., Simunin M.M. Induced-charge enhancement of diffusion potential in membranes with polarizable nanopores. Physical Review Letters, 2017. V. 119, 226001.

https://doi.org/10.1103/PhysRevLett.119.226001

39. Ryzhkov I.I., Lebedev D.V., Solodovnichenko V.S., Minakov A.V., Simunin M.M. On the origin of membrane potential in membranes with polarizable nanopores. Journal of Membrane Science, 2018. V. 549. P. 616-630.

https://doi.org/10.1016/j.memsci.2017.11.073

40. Lebedev D.V., Solodovnichenko V.S., Simunin M.M., Ryzhkov I.I. The influence of electric field on the ion transport in nanoporous membranes with conductive surface. Petroleum chemistry, 2018. V. 58 (6), P. 474-481.

41. M. Aghayan, M. Gasik, I. Hussainova, et al. Thermal and microstructural analysis of doped alumina nanofibers, Thermochimica Acta $602 \quad$ (2015) 43-48 http://dx.doi.org/10.1016/j.tca.2015.01.009

42. Design and control of structure of advanced carbon materials for enhanced performance. Edited by B. Rand, S.P. Appleyard, M. F. Yardim, NATO Science Series E, 2001. ISBN 978-94-010-1013-9

43. A.C. Ferrari, D.M. Basko. Raman spectroscopy as a versatile tool for studying the properties of graphene. Nature Nanotechnology, $8 \quad$ (2013) 235-246 http://dx.doi.org/10.1038/nnano.2013.46

44. A.G. Pandolfo, A.F. Hollenkamp. Carbon properties and their role in supercapacitors, J. Power Sources 157 (2006) 11-27. https://doi.org/10.1016/j.jpowsour.2006.02.065

45. T.D. Tran, K. Kinoshita, Proceedings of the Electrochemical Society. 98-15 (1998) p. 548. 